\title{
Nietzsche: por una política del individuo ${ }^{1}$
}

\section{Nietzsche: for a Politics of the Individual}

\author{
Maria Cristina Fornari ${ }^{2}$ \\ Università del Salento (Italia) \\ ORCID: https://orcid.org/0000-0001-8756-528X
}

Recibido: 14-01-2021

Aceptado: 28-01-2021

\section{Resumen}

Aunque Nietzsche nunca formuló una teoría política real, su crítica de la modernidad y la búsqueda de soluciones alternativas para una elevación del "tipo humano" son ciertamente parte de un proyecto de "große Politik", que sin embargo pertenece más a la esfera de la filosofía y la cultura que a la de una ciencia del gobierno. En oposición a las organizaciones homologadoras - políticas, económicas, morales- que han robado las energías más peculiares del hombre, Nietzsche trabaja por la promoción de una individualidad fuerte que por sí sola pueda puede prometer construcciones duraderas. La originalidad y la capacidad de incorporar elementos disonantes son para Nietzsche síntomas de una cultura superior: el "buen europeo" del futuro será, por tanto, quien, más allá de las estrechas fronteras personales y nacionales, sabrá abrirse a fructíferas hibridaciones.

Palabras-clave: Nietzsche, Grande politica, Individuo, Democrazia, Tocqueville.

\footnotetext{
${ }^{1}$ Este artículo constituye una reelaboración de „Nietzsche und die politische Philosophie“, en: Handbuch Nietzsche und die Wissenschaften des 19. Jahrhunderts, Ed. by Heit, Helmut / Heller, Lisa, de Gruyter, Berlín, 2014, pp. 322-340.

2 (mcfornari@gmail.com). Profesora de Historia de la filosofía contemporánea, investigadora del grupo Internazionale di Recherche su Nietzsche (GIRN) y del Seminario permanente Nietzsche, es asimismo investigadora asociada del Institut des Textes et Manuscrits Modernes (CNRS, París), colaboradora con Giuliano Campioni en la edición crítica de las obras y el epistolario de Nietzsche en italiano y codirectora de la colección Nietzscheana (ETS, Pisa). Entre sus publicaciones sobre Nietzsche destacan La morale evolutiva del gregge. Nietzsche legge Spencer e Mill (ETS, Pisa, 2006) y Nietzsche y el evolucionismo (Córdoba, Argentina, Brujas, 2016).
} 


\begin{abstract}
Although Nietzsche never formulated an actual political theory, his critique of modernity and his search for alternative solutions to raise the 'human type' are certainly part of a "große Politik" project, which, however, belongs more to the realm of philosophy and culture than to that of a science of government. In opposition to homologating organisations -political, economic, moral- that have robbed man of his most peculiar energies, Nietzsche works for the promotion of a strong individuality that alone can promise lasting constructions. Originality and the ability to incorporate discordant elements are, for Nietzsche, symptoms of a superior culture: the 'good European' of the future will therefore be the one who, beyond narrow personal and national boundaries, will be able to open up to fruitful hybridisation.
\end{abstract}

Key-words: Nietzsche, Politics, Individual, Democracy, Tocqueville.

1.

A pesar del innegable uso político que se ha hecho y se sigue haciendo de sus escritos y su filosofía, con resultados al menos cuestionables ${ }^{3}$, Nietzsche nunca expuso una teoría política completa, ni definió de manera exhaustiva los conceptos tradicionalmente relacionados con esta disciplina ${ }^{4}$. Estado,

\footnotetext{
${ }^{3}$ Como es bien sabido, desde fecha temprana Nietzsche fue leído, por la derecha, como un teórico del "radicalismo aristocrático" (según una conocida definición de Brandes, 1888) y luego como precursor del germanismo (Baeumler); por la izquierda, como "maestro de la sospecha" y gran crítico de las ideologías, hasta las distorsiones posmodernas (o posmodernistas) de la Nietzsche-Renaissance francesa. Si los intentos de instaurar, a través de Nietzsche, una "filosofía de la diferencia" que también fuera una "filosofía de la liberación" (Derrida, Foucault) parecen hoy dejados de lado, por el contrario, siguen vivas las tentaciones de quienes aspiran a un Nietzsche anti-libertario, cuyo pensamiento contendría "motivos turbios y repugnantes" (Losurdo: 2002) que encuentran su aplicación real en la filosofía del tercer Reich (Ferraris: 1991). A todas estas interpretaciones, que, a pesar de lo que declaran, carecen de una contextualización histórica seria y de una reconstrucción honesta de la biografía intelectual de Nietzsche, se opone con fuerza la lectura histórico-filológica de la edición crítica de Colli-Montinari, que ha contribuido a liberar a Nietzsche de cualquier distorsión ideológica, en particular con la publicación cronológica y correcta de sus textos (incluidos los fragmentos póstumos) y con la restitución a su propio ámbito cultural. Para una revisión bibliográfica del tema del Nietzsche "político", en particular en sus relaciones con la democracia, resulta provechoso vid. Siemens: 2001. Se ha dado también mucho espacio, en la discusión, al tema del agon: además del mencionado Siemens, véanse los trabajos de Acampora, quien lee agon y lucha "como un espacio cultural y social para la creación de un sentido del bien público, una práctica de creación de sentido [...] [Nietzsche] no es simplemente un defensor de una forma de nobleza homérica que justifica el poder o la celebración de la valentía. Más bien, la visión de Nietzsche de agon se despliega en un intento de una interpretación integral de la vida" (Christa Davis Acampora, Demos Agonistes Redux: Reflections on the Streit of Political Agonism, "Nietzsche-Studien", 32 (2003), pp. 373-89: 377).

${ }^{4}$ Según una definición actual de ciencia y sociología política (ver Noberto Bobbio, "Stato, potere e governo" En: Stato, governo, società. Frammenti di un dizionario politico, Turín, Einaudi 1985),
} 
instituciones, derechos, sociedad civil, si han sido su objeto de interés, lo han sido de modo colateral, en el curso de su crítica a la modernidad y poniendo el foco de atención en sus estructuras decadentes, con vistas, propiamente, a una "große Politik" que constituya un contra-movimiento, pero que pertenece más al ámbito de la filosofía y la cultura que al de una ciencia de gobierno.

La conocida imagen, tomada de Jacob Burckhardt, de los Gewaltmenschen (literalmente, "hombres de violencia") como futuros "señores de la tierra" y posibles plasmadores de una nueva humanidad, recuerda más bien el modelo de una aristocracia de la Kultur capaz de ejercicio de la virtud "libre de moralina"5; y las proclamas de tono político, que encontramos, por ejemplo, en el Ecce homo o en Crepúsculo de los ídolos -con sus metáforas guerreras y disruptivas- transmiten en realidad una postura estética, que implica carácter y "gran estilo". El Gewaltmensch es, de hecho, "un hombre filosófico violento y un tirano artista", formado con una dura autolegislación y disciplina, cuya determinación quedará impresa en los milenios gracias a "una sobreabundancia de voluntad, conocimiento, riqueza, influencia" . Sólo atendiendo a las formas más bajas de Wille zur Macht se puede plantear la hipótesis de que la "gran política" coincida con la brutal "necesidad de un sentimiento de poder", que todavía habla el lenguaje de la moralidad y que Nietzsche ya estigmatiza en el aforismo de Aurora $^{8}$.

estas disciplinas se caracterizan sobre todo por una intención principalmente descriptiva y analítica de fenómenos y procesos donde la filosofía política intentaría comprender sus estructuras profundas, ocultas, no visibles de inmediato a la mirada fenoménica. En cuanto filosofia, siempre trataría de problematizar lo que es o parece evidente, habitual y pragmáticamente aconsejable, reconectando sus interpretaciones, valoraciones y elecciones últimas a procesos y mecanismos no aparentes. En este sentido, podríamos estar de acuerdo en que Nietzsche sea, de hecho, un filósofo político.

${ }^{5}$ Cfr. FP 1881 11[197]; FP 1884 25[117]. Cfr. Carlo Gentili, Grande politica e pathos della distanza. La concezione politica e morale di Nietzsche, "Palomar", Vol. 2/3 (2005), pp. 96-106: 102-103; Giuliano Campioni: Der französische Nietzsche, Berlin/New York, Walter de Gruyter 2009, cap. 4.

${ }^{6}$ Cfr. al respecto Carlo Gentili, Nietzsche politico o apolitico? "Estudios Nietzsche" 12 (2012), pp. $10-11$.

7 Vale la pena leer el fragmento en su integridad: "A partir de ahora se darán precondiciones favorables para formaciones de dominio más abarcadoras, como no ha habido todavía nada similar. Y esto no es aún lo más importante: se ha vuelto posible que surjan estirpes internacionales que se impongan la tarea de criar una raza de señores, los futuros 'señores de la tierra'; - una nueva, prodigiosa aristocracia, edificada sobre la más dura autolegislación, en la que se dará una duración más que milenaria a la voluntad de hombres filosóficos violentos y tiranos artistas: - un género superior de hombres que, gracias a su supremacía en el querer, en el saber, en riqueza y en influencia, se servirían de la Europa democrática como el más flexible y dúctil de sus instrumentos para tomar en sus manos los destinos de la tierra, para dar forma como artistas que trabajen sobre el 'hombre' mismo. Suficiente, llega un tiempo en el que en política se aprenderá a pensar de otro modo" (FP 1885 2[57]).

8 "De la gran política. Por mucho que en la gran política también intervengan la utilidad y la vanidad de individuos y de pueblos: la corriente que con mayor fuerza la impulsa es la necesidad de sentir poder, que no sólo puja en las almas de príncipes y poderosos, sino que de vez en cuando, de fuentes inextinguibles, lo hace también en las capas inferiores del pueblo, y en no escasa medida. [...] Los grandes conquistadores han llevado siempre en la boca el lenguaje patético de la virtud; en derredor siempre tenían masas que se hallaban en estado de exaltación y sólo querían escuchar el más exaltado de los lenguajes" (M, 189). 
Podemos convenir con Ansell-Pearson en que lo que Nietzsche ha planteado siempre ha sido más bien "un conflicto permanente entre cultura y política": y si los fines y peculiaridades de una cultura están necesariamente condicionados por la organización de la sociedad, por las relaciones económicas, de naturaleza, posición y rol de los individuos y de los valores de los que son portadores, esto sucede desde el trasfondo de ese contraste, siempre reiterado por Nietzsche y explicitado, nuevamente con acento burckhardtiano, en Crepúsculo de los ídolos:

Si uno se dedica al poder, a la gran política, a la economía, al comercio mundial, al parlamentarismo, a los intereses militares -si a favor de esa parte disipa el quantum de intelecto, de seriedad, de voluntad, de auto-superación que uno es, entonces esto falta en la otra parte. La cultura y el Estado -no nos engañemos al respecto- son antagonistas: el 'Estado de cultura' es simplemente una idea moderna. Lo uno vive de lo otro, lo uno prospera a expensas de lo otro. Todas las épocas grandes de la cultura son épocas de decadencia política: lo que es grande en el sentido de la cultura ha sido apolítico, incluso antipolítico ${ }^{10}$.

A despecho de la Realpolitik, la batalla cultural se resuelve para Nietzsche, como es bien sabido, a favor de Francia y contra el Reich alemán y la Alemania bismarckiana, por los que el filósofo expresa su descontento desde sus años juveniles. En una época en la que, ante la idolatría de la economía y la política, se desperdicia "lo más precioso, el espíritu" "11 los alemanes no sólo se han liberado de su cultura ancestral ("que hoy ya no poseen, de la que incluso se han deshecho con una pasión ciega, como si de una enfermedad se tratara"), sino que no se les ha ocurrido nada mejor que cambiarla por un delirio político y nacionalista ${ }^{12}$. Al Nietzsche orgullosamente apátrida, cosmopolita e incluso deseoso de "renacer en el mundo como francés"13, la Alemania estúpida le resulta cada vez más distante y hostil: su mirada atenta y de largo alcance es muy crítica con el oscurantismo que avanza, con la gran política grandilocuente, pero que en realidad es la mezquina política de los resentimientos y las reivindicaciones chovinistas ("Los alemanes corrompen, como rezagados, el gran rumbo de la cultura europea..."14).

\footnotetext{
9 Keith Ansell-Pearson: An Introduction to Nietzsche as political Thinker. The perfect nihilist, Cambridge, Cambridge University Press 1994, p. 3.

${ }^{10} \mathrm{GD}$, Lo que les falta a los alemanes, 4 . Esto vale también desde el punto de vista de las condiciones personales: por ejemplo, “¡Lo mínimo de Estado posible! No necesito del Estado, sin esa coacción tradicional me habría procurado una mejor educación, una educación más adecuada a mi cuerpo, y me habría ahorrado la fuerza qure se desperdicia luchando por liberarse. ¡Que las cosas a nuestro alrededor serían más inseguras, tanto mejor! [...] Yo mismo quiero ser tanto Estado cuanto sea posible, tengo tantas excepciones, tantos ingresos, tantas necesidades, tanto que compartir. Al mismo tiempo, pobre y sin perspectiva de cargos honoríficos, sin admirar tampoco los laureles guerreros" (FP 1880 6[377]).

${ }^{11}$ M 179.

12 M 190.

${ }^{13}$ Cfr. carta a J. Bourdeau, en torno al 17.12.1888.

14 FP $188425[115]$.
}

Araucaria. Revista Iberoamericana de Filosofia, Politica, Humanidades y Relaciones Internacionales, año $23, \mathrm{n}^{\circ} 46$. Primer cuatrimestre de 2021. Pp. 273-289. ISSN 1575-6823 e-ISSN 2340-2199 https://dx.doi.org/10.12795/araucaria.2021.i46.13 
Si en las últimas cartas, dirigidas a interlocutores reales e hipotéticos poco antes del colapso psíquico, la casa Hohenzollern es vista como guarida del atraso cultural y de una obtusa política nacionalista ${ }^{15}$, la distancia se convierte ya en hostilidad frente a las distintas manifestaciones de antisemitismo, que Nietzsche rechaza con firmeza ${ }^{16}$ :

Este partido me ha echado a perder, uno tras otro, a mi editor, mi prestigio, a mi hermana, a mis amigos- nada es un estorbo mayor para mi influencia que el hecho de que el nombre de Nietzsche se haya puesto en relación con antisemitas tales como Dühring: no se me ha de tomar a mal que recurra a la legítima defensa ${ }^{17}$.

Mientras, piensa en determinados pueblos o castas capaces de proporcionar almas más fuertes y grandes de cuantas han existido hasta ahora ("Centralizar todas las capacidades individuales del pasado en una única naturaleza. Posición de los judíos para este propósito") ${ }^{18}$. La acción de Nietzsche en pos de una "gran política" no está, por tanto, ligada al proyecto filosófico y sistemático de la Voluntad de Poder, que se malinterpreta con facilidad y a menudo, de hecho, deliberadamente. La "gran política" es más bien el proyecto de una nueva cultura $^{19}$, que debe liberarse de la moral tradicional -cuyos productos han dado pésima prueba de sí, en sentido social y cultural- orientada hacia un nuevo tipo humano, cuya definición es cualquier cosa menos unívoca ${ }^{20}$.

15 "Representa la forma más estúpida, degenerada y falsa del 'espíritu alemán' que ha existido hasta ahora" (carta a C. von Seydlitz, 24.2.1887); “El príncipe Bismarck jamás ha pensado en el 'Reich' -iél es en todos sus instintos tan sólo un instrumento de la casa Hohenzollern!- iy esta instigación al egoísmo de los pueblos se siente y se enseña en Europa como una gran política, casi como un deber! ... Tenemos que terminar con esto -y soy lo suficientemente fuerte para ello..." (carta a R. Bonghi, finales de diciembre de 1888).

${ }^{16}$ El conocimiento por parte de Nietzsche del antisemitismo y sus diversas expresiones se profundiza no sólo a partir de la lectura de los "clásicos" del movimiento (Dühring, Lagarde o el "Bayreuther Blätter"), sino también a través del contacto con importantes exponentes de varias organizaciones antisemitas: desde el editor Schmeitzner hasta su cuñado Förster. En las cartas del último período, sus opiniones sobre la empresa de fundación de una colonia aria en Paraguay, emprendida por su hermana y su esposo, son inequívocas: "Finalmente, es mi deseo que los alemanes acudan en su ayuda de alguna manera, obligando a los antisemitas a abandonar Alemania: y no hay duda de que, en este caso, preferirían Paraguay, su tierra "prometida", a otros países ... Estoy sinceramente convencido: un alemán que sólo por ser alemán pretende ser más que un judío es un personaje de comedia: suponiendo que no lo sea de manicomio" (carta a Elisabeth Förster-Nietzsche, poco antes del 5 de junio de 1887). Losurdo demuestra que no conoce (o no tiene en cuenta) estas últimas cartas, cuando ve una prueba del antisemitismo de Nietzsche en sus relaciones con el editor Schmeitzner, quien lo hubiese querido como aliado, pero con quien Nietzsche, en cambio, rompe definitivamente relaciones (cfr. Domenico Losurdo, Nietzsche, il ribelle aristocratico. Torino, Bollati Boringhieri 2002: pp. 605, 608 ss.).

${ }^{17}$ Carta a Franziska Nietzsche, 29.12.1887. Amplia información sobre este tema en "Notizie e note" a: F. Nietzsche, Epistolario 1885-1889, al cuidado de G. Campioni e M.C. Fornari, Adelphi, Milano, 2011.

${ }^{18}$ FP $1884,25[221]$ e [222].

19 Véase, sin embargo, Ottmann: "La última filosofía de Nietzsche se diferencia de la del espíritu libre en un punto esencial. La apolítica del espíritu libre ya no es el ideal de Nietzsche. El "superhombre" [...] debe ser soberano [...] 'gran política' en Nietzsche significa dominio" (Henning Ottmann: Philosophie und Politik bei Nietzsche, Berlin, de Gruyter 1987, p. 239).

${ }^{20}$ Bastaría la irritada declaración de Ecce homo ("Otros doctos animales cornudos me han acusado 
Frente a la "barbarie domesticada" que avanza en Europa ${ }^{21}$, la ambición de Nietzsche es la de brindar una alternativa capaz de contrarrestar el nihilismo y emplear provechosamente las energías puestas en marcha en el campo de la decadencia: "Moralidad - la quintaesencia de todas las valoraciones incorporadas a nosotros: ¿qué va a ser de esta enorme suma de energía? Sólo a este respecto me interesa la cuestión de cómo surgen estas valoraciones"22, afirma en un apunte, confirmando la idea de una destinación "económica" de sus consideraciones.

Una sociedad fundada en valores absolutos es de hecho incapaz de comprender la "economía general del conjunto". Más aún: una sociedad basada en valores instrumentales y utilitarios, determinada por el poder político y guiada por una economía monetaria, como Nietzsche cree que es la moderna, resulta incapaz de crear construcciones estables y culturalmente significativas ${ }^{23}$. Convertidos en "arena blanda" y en "hierro de madera", ya no somos material adecuado para una sociedad ${ }^{24}$ : el predominio del altruismo y la compasión, la aspiración a la felicidad y el pequeño bienestar, la reivindicación de la igualdad de derechos y la homologación de gustos y tendencias, feroces herramientas niveladoras tomadas del mercado, "corroen y destruyen formas características" ${ }^{25}$.

por ello de darwinismo": EH, Por qué escribo libros tan buenos, 1) para socavar la idea de que el "nuevo tipo" defendido por Nietzsche es producto de una especie de eugenesia. Y si es innegable que Nietzsche piensa en una nueva configuración (Gestaltung) del hombre confiada a la reorganización de su sistema psicofísico, quizás no esté tan claro cuáles son los medios para implementar esta "revolución" o "guerra de espíritus".

${ }^{21}$ Cfr. FP $188425[121]$.

22 FP 1882 4[151]. "El nuevo proyecto alternativo [de Nietzsche] comporta una reorganización de la cantidad total de energía disponible para la humanidad. Esta fuerza es constante y finita en cantidad (Nietzsche insiste en este aspecto antiteleológico) y puede organizarse, como pretenden los demócratas y socialistas, a través del presupuesto de la fundamental igualdad de derechos para todos: un presupuesto de tipo moral que conduce a la elaboración de 'homo communis y un debilitamiento general. O bien, como es necesario para el superhombre, se trata de considerar a todos los demás como energía necesaria para su fortalecimiento y realización. Tomando nota del carácter de esclavos de la mayoría de los hombres, la nueva conciencia noble pretende dar sentido a su existencia. No es momento de entrar ahora en los detalles de la ardua y discutida problemática que conlleva esta "política". Me interesa, en cambio, mostrar cómo la recuperación "económica" de la religión y la moral cristianas, la valoración de la ciencia y, paradójicamente, incluso de la democracia, se produce en esta dirección. Sobre todo este último punto, conectado además al anterior, ha dado lugar al menos a tanta ambigüedad en las interpretaciones, como claridad había en los textos de Nietzsche" (Giuliano Campioni, Sulla strada di Nietzsche, Pisa, ETS 1993, pp. 193-94).

${ }^{23}$ Cfr. Ansell-Pearson, op. cit., p. 5.

${ }^{24}$ Cfr. FW 356; FP 1880 3[98]). La fuente de este símil es Alexis de Tocqueville, mediado por John Stuart Mill: cfr. Maria Cristina Fornari, La morale evolutiva del gregge. Nietzsche legge Spencer e Mill, Pisa, ETS 2006, pp. 272 sgg.

${ }_{25}$ Cfr. FP 6[163] 1880. Las categorías económicas caras al liberalismo contemporáneo simplifican una situación real compleja: equilibrar pesos y medidas, establecer equivalencias, establecer un "precio" para cada situación, presupone creer en acciones intercambiables, por lo tanto, en un individuo masificado, que no puede producir, en valor, más que el promedio de sus semejantes. Cfr. M 174; M 175; 1887 9[55]; 1887-1888 11[127]; 1888 22[1]. 
Frente a esta improductiva situación determinada por la modernidad, Nietzsche valora las posibilidades abiertas por la decadencia y la enorme riqueza que trae consigo. En este sentido, el punto de vista gregario -objetivo polémico constante de Nietzsche- es sólo uno entre muchos, funcional respecto al reforzamiento del tipo corriente y situado por debajo en relación a posibles aperturas de perspectiva. "Una vez que se ha logrado este objetivo, se puede aspirar más alto" 26 a través de una feliz mezcla de opuestos, en contraste con la unilateralidad de ciertos individuos o pueblos y su orden de valores ${ }^{27}$.

Justamente al contrario de las salidas, a menudo malentendidas y exasperadas con las que se ha pretendido leer, el proyecto de un nuevo tipo humano no expresa por tanto un deseo de abrumar o imponer una determinada perspectiva. Más bien, como apertura a tantos puntos de vista como sea posible, se opone a la estrecha perspectiva del individuo actual, que se impone -él síegoístamente, a través de una lectura unidireccional de sus afectos ${ }^{28}$. Si el tipo gregario, particularmente estable en su configuración, es en realidad obtuso y tiránico ("tiranía de una especie que no reconoce su propia relatividad"29), es, por el contrario, una suerte de experimentación consigo mismo lo que constituye el rasgo del tipo superior, que tiene mucho menos de carácter dominante que de la frágil complejidad de una forma híbrida y plural. El creciente interés de Nietzsche, en los últimos años, por el fenómeno de la décadence, hará que la torpeza del filisteo se oponga cada vez más a configuraciones caracterizadas por una mayor riqueza de impulsos, premisa necesaria para una cultura superior. Sólo este material experimental puede aspirar a contrarrestar el proceso de Verkleinerung del hombre moderno: la decadencia proporcionará así a la crisis una salida posible, para oponerse en particular a las estructuras graníticas hijas del cristianismo, pero también del positivismo y un cierto naturalismo moral.

${ }^{26}$ Cfr. FP 1883 7[21]; 1884 25[211].

${ }^{27}$ La idea absolutamente actual de los "buenos europeos" como aquellos que han abandonado (o van a abandonar) las estrechas fronteras nacionales - geográficas y culturales- para abrirse a la contaminación, encaja en esta perspectiva. Sobre el concepto de "buen europeo", véase, entre otros, Pietro Gori y Paolo Stellino, Il buon europeo di Nietzsche oltre nichilismo e morale cristiana, "Giornale critico della filosofia italiana", 7 serie, vol. XII, a. 95 (1), 2016, pp. 98-124; Daniel W. Conway, Nietzsche \& the Political, London, Routledge 1997. Conway habla de una "micropolítica" de resistencia en Nietzsche, frente a una "macropolítica" de transformación. La macropolítica se refiere a la "producción de grandes individuos a través de la organización de los recursos institucionales", mientras que la micropolítica opera fuera de los marcos institucionales, dentro de la "red de la vida ética" que es su fuente. El "perfeccionismo ético" vehicula, por tanto, el "perfeccionismo político", que nunca es nada más que su instrumento (cf. Conway, op. cit., p. 48). Pero Conway enfatiza más bien la dimensión performativa de los escritos de Nietzsche y no lee en la política sino una semiótica de la auto-creación. Véase también Herman Siemens, Nietzsche and Agonistic Politics: A Review of Recent Literature, "Nietzsche-Studien", 30 (2001), pp. 509-526: 510-11.

${ }^{28}$ Cfr. FP 1884, 27[171].

${ }^{29}$ Campioni, Sulla strada di Nietzsche, cit., p. 190. La configuración gregaria tiene de su lado milenios de adaptación evolutiva a un entorno hostil y dominado por el miedo: esto hace que las actitudes protectoras y conservadoras prevalezcan y se fijen, como instintos, en la genuina memoria orgánica de la especie.

Araucaria. Revista Iberoamericana de Filosofía, Política, Humanidades y Relaciones Internacionales, año $23, \mathrm{n}^{\circ} 46$. Primer cuatrimestre de 2021. Pp. 273-289. ISSN 1575-6823 e-ISSN 2340-2199 https://dx.doi.org/10.12795/araucaria.2021.i46.13 
Comercio y bienestar, mercado y confort: éstas son las palabras-clave en las que se centra la crítica de Nietzsche, en particular a partir de la década de los años 80, a las construcciones morales, sociales, políticas y económicas contemporáneas, en las que lee la causa y a la vez la consecuencia del proceso de debilitamiento del hombre moderno. Sus fuentes, en este caso, son principalmente evolucionistas, utilitaristas, sociólogos organicistas, y en general quienes, en busca del bienestar general, en lugar de aspirar a una emancipación real del individuo, le imponen supuestos propósitos "naturales", lo incrustan en estructuras colectivas y lo transforman en una función útil del todo ${ }^{30}$.

Nietzsche, en cambio, está cada vez más convencido de que el progreso reside en el elemento perturbador de la originalidad ${ }^{31}$ : el imperativo utilitarista, "actuar siempre de la manera más útil para la comunidad", con el que, por ejemplo, Stuart Mill ha distorsionado la fórmula del imperativo kantiano y ha camuflado la Regla de Oro, está destinado sólo a individuos homogéneos, con las mismas necesidades y medios suficientes para satisfacerlas; es un imperativo para la sociedad actual, pero una abstracción completamente inutilizable para toda sólida construcción futura ${ }^{32}$.

La reducción del individuo a un concepto colectivo del tipo que sea, su inclusión en un organismo en el que puede esconderse y refugiarse de sus propias idiosincrasias ${ }^{33}$, equivale a una sustracción de sus características

30 "Se reconozca o no -lo que se pretende es nada menos que una reforma radical del individuo, esto es, su debilitamiento y anulación; no se cansa uno de hacer recuento y de denunciar todo el mal y la hostilidad, el despilfarro, la carestía y el lujo que la forma de existencia individual habida hasta ahora comportan, y se confía en que si sólo quedan grandes colectividades con sus miembros, la organización económica será más barata, inofensiva, equilibrada y unificada. Todo lo que contribuya a dar forma directa o indirecta a esas colectividades y esos miembros se considera bueno, tal es la corriente moral de fondo de nuestra época; en ella se mezclan, hasta confundirse, empatía y sensibilidad social" (M 32; cfr. FW 119). Sobre esta temática me permito remitir a Fornari, 2006.

${ }^{31}$ Esto, ya desde Humano, demasiado humano, del cual puede verse el conocido y significativo aforismo 224, Ennoblecimiento por degeneración. Que la originalidad sea un factor de progreso es también la tesis de Stuart Mill: Nietzsche encuentra una amplia discusión al respecto en el ensayo Sobre la libertad, de 1859, que lee en la traducción alemana en el volumen I de las Gesammelte Werke, de John Stuart Mill, Leipzig: Fues 1869-1880 (en su biblioteca personal se conservan hoy los volúmenes I, IX-XII, con numerosos subrayados, que parecen mostrar a Nietzsche de acuerdo).

32 "El propósito que intenta igualdad de derechos y finalmente igualdad de necesidades, consecuencia prácticamente inevitable de nuestra forma de civilización del comercio y de la equivalencia política de los votos, trae consigo la exclusión y la lenta extinción de los seres humanos superiores, más peligrosos, más extraordinarios e, in summa, más nuevos: el experimentar, por así decirlo, se acaba, y se alcanza un cierto estancamiento en un punto muerto" (FP 11[157] 1887-88).

33 "Todo lo contrario de lo que yo pretendo- afirmará Nietzsche - separar el mayor número posible de organismos diferentes y variados que, llegados a la madurez y descomposición, dejen caer su fruto, los individuos, de los cuales ciertamente la mayoría perece, pero lo que importa son los pocos" (FP $188111[222])$. 
peculiares $^{34}$; la pretendida igualdad de condiciones, sustentada una vez más por una disposición gregario-cristiana encarnada, da lugar a organizaciones sociales y políticas artificiales caracterizadas por aspiraciones rencorosas ${ }^{35}$.

Con palabras análogas a las de Alexis de Tocqueville, del que es lector inesperado ${ }^{36}$, Nietzsche mira con preocupación el advenimiento de la democracia, entendida no tanto como una forma particular de gobierno, sino como el venir a menos de toda disposición aristocrática ${ }^{37}$.

Una ilusoria intercambiabilidad de valores y de roles da rienda suelta de hecho al diletantismo y al parvenue de la política ${ }^{38}$; la opinión pública, con su

34 "En cuanto pretendemos determinar cuál es el fin del hombre, estamos presuponiendo un concepto de hombre. Mas sólo hay individuos, de lo hasta ahora conocido sólo obtenemos un concepto a cambio de desentendernos de lo individual -por eso, establecer el fin del hombre significaría impedir que los individuos lleguen a ser individuales, conminándoles a ser universales. ¿No debería ser al revés, que todo individuo supusiera la tentativa de lograr, gracias a lo que de individual tuviera, una especie superior a la del hombre? Mi moral sería la de ir suprimiendo en los hombres lo que de universal tienen, en ir especializándolos, hacerlos hasta cierto punto incomprensibles para los demás (y, así, objeto para ellos de vivencias, de asombro, de enseñanza)" (FP 6[158] 1880). La posición de Nietzsche, señala Ansell-Pearson, no puede tildarse de "liberal", en la medida en que aspira a una afirmación real del individuo y no a la mera libertad social y económica (laissez-faire) del ciudadano burgués. En un sistema dominado por el dinero y por una improbable igualdad, la afirmación del "individuo soberano" resulta imposible. El de Nietzsche es más bien un "individualismo aristocrático", que Ansell-Pearson califica también como "antihumanismo", "donde el humanismo se entiende en el sentido de poner al hombre en el centro del universo e interpretar su valor a partir de una perspectiva humana / moral" (cf. Ansell-Pearson, op. cit., p. 9 y sigs.).

35 "a la humanidad se le ha enseñado a balbucear primero de manera religiosa el principio de igualdad, posteriormente de ellos se le ha hecho una moral: ¡y de qué asombrarse si el ser humano acaba tomándolo en serio poniéndolo en práctica! Quiero decir, asumiéndolo políticamente, democráticamente, mediante el socialismo, mediante el pesimismo de la indignación..." (FP 1888 15[30]).

${ }^{36}$ Nietzsche lee con gran atención la reseña de John Stuart Mill sobre La democracia en América, que apareció en la "Edinburgh Review" en 1840 (en el volumen XI de Gesammelte Werke de John Stuart Mill), inspirándose en ella para sugerencias importantes. Cfr. supra, nota 23.

${ }^{37} \mathrm{Si}$ la irresistible tendencia hacia la democratización es para Tocqueville un hecho providencial destinado a aumentar, que discurre demasiado rápido como para poder detenerlo, pero no tanto como para no poder dirigirlo, de ello se hace eco Nietzsche: "Considero el movimiento democrático como algo inevitable: pero como algo que no es irresistible, sino que se puede retardar. Pero en general crecen juntos el dominio del instinto gregario $\mathrm{y}<$ de las $>$ estimaciones de valor gregarias, el epicureísmo y la benevolencia: el hombre se debilita, pero se hace bueno y agradable" (FP 34[108] 1885). Dos años más tarde, Nietzsche será más radical, cuando reitere con fuerza la necesidad de una funcionalización de la energía a las características distintivas del poder; en esta perspectiva, "la nivelación del hombre europeo es el gran proceso que no hay que obstaculizar; se lo debería acelerar aún más. Está así dada la necesidad de abrir un abismo, de distancia, de jerarquía: no la necesidad de ralentizar aquel proceso" (FP 9[153] 1887). Véase en ese sentido JGB 242, cuya síntesis suena así: "Yo he querido decir: la democratización de Europa es al mismo tiempo una organización involuntaria para la crianza de tiranos, -tomada la palabra en todos sus sentidos, también en el más espiritual".

38 "Cuando todas las prerrogativas de nacimiento y fortuna son abolidas, cuando todas las profesiones están abiertas a todos y se puede alcanzar la cúspide de ellas, ante la ambición de los hombres parece abrirse un campo inmenso y fácil, y ellos imaginan de buena gana estar llamados a grandes destinos. Pero es una condición falaz, que la experiencia corrige todos los días: esa misma igualdad que permite a todo ciudadano concebir grandes esperanzas, debilita individualmente a todos los ciudadanos. Permite que sus deseos se expandan, pero, al mismo tiempo, limita sus fuerzas por todas partes. [...] Habiendo destruido los privilegios de algunos de sus semejantes, ahora se enfrentan a la competencia de todos. Las correas han cambiado más de forma que de lugar. Cuando los hombres son más o menos iguales y todos siguen el mismo camino, es muy difícil para alguno 
nivelación de opiniones, gustos, tendencias y metas - una verdadera "tiranía de la mayoría" - teme y obstaculiza el crecimiento de naturalezas originales y poderosamente individuales:

En lugar de una gran energía guiada por una mente rigurosa, y sentimientos robustos controlados por una voluntad consciente, no se obtienen más que caracteres desvirilizados y ánimos débiles, capaces únicamente de ajustarse, en apariencia, a la regla, sin hacer un gran esfuerzo de su voluntad y su razón. Los personajes viriles son ahora casi legendarios ${ }^{39}$.

Al incremento de la sociedad democrática le corresponde, por tanto, una especie de atrofia individual y parece escucharse al propio Nietzsche en este caveat de Tocqueville:

El carácter general de las sociedades antiguas era la diversidad. Se desconocía la unidad y la uniformidad. En el nuestro, por el contrario, todo amenaza con volverse tan igual, que la individualidad específica de cada individuo anda a punto de perderse totalmente en la fisonomía común. Nuestros padres siempre estuvieron dispuestos a abusar de la idea de que los derechos privados debían ser respetados y nosotros, en cambio, tenemos una inclinación temperamental a exagerar la contraria, que el interés individual debe plegarse continuamente al interés de la mayoría. El mundo político cambia; ahora debemos buscar nuevos remedios para nuevos males. Fijar límites al poder, amplios, pero seguros e inquebrantables; otorgar a las personas determinados derechos y garantizarles el goce indiscutible de los mismos; conservar para el individuo la poca independencia, fuerza, originalidad que le queda; devolverle la dignidad junto a la sociedad y apoyarle ante ella: este parece ser el primer objetivo del legislador en la época en la que estamos entrando. Parece que los gobernantes de nuestro tiempo no intentan hacer con los hombres grandes cosas. Me gustaría que pensaran un poco más en crear grandes hombres ${ }^{40}$.

Nietzsche comparte, así pues, el temor a que Europa se encamine hacia una progresiva "chinoiserie" 41 , testigo de su extenuación, y augura la presencia de

de ellos caminar más rápido y abrirse paso entre la multitud que lo rodea y lo aprieta” [...]. Mientras que cualquiera es devorado por la ambición, difícilmente se es ambicioso de gran estilo" (J.S. Mill, Sobre La democracia en América, trad. al. cit., pp. 45-46; las cursivas corresponden al subrayado de Nietzsche, que marca de manera llamativa todo el pasaje en el margen de su ejemplar personal).

${ }^{39}$ Estas palabras, que podrían ser de Nietzsche, pertenecen en cambio al liberal Stuart Mill: Nietzsche traza una vistosa línea de subrayado al margen de este pasaje de On Liberty, trad. al. cit., p. 72.

40 J.S. Mill, Sobre La democracia en América, trad. al. cit., p. 49. Las cursivas corresponden a los subrayados de Nietzsche en su ejemplar personal.

${ }^{41}$ La metáfora del "chino" como prototipo del engranaje de la máquina moderna, un individuo perfectamente alineado con sus propias condiciones de existencia, es recurrente en la literatura de la época: Nietzsche, que la utiliza ampliamente a principios de los años ochenta y, más tarde, en Más allá del bien y del mal y en La genealogía de la moral, la encuentra en Schopenhauer, Flaubert, Renan y, en general, en publicaciones políticas; pero su fuente principal es una vez más Stuart Mill, quien en On Liberty la emplea para denotar a un pueblo ahora subordinado a la tiranía del conformismo. 
elementos perturbadores -que en Crepúsculo de los ídolos resume en la figura del "chandala" - capaces de sacudirla e inocularle lo nuevo. Se trata de fuerzas primitivas, impetuosas, indisciplinadas, muchas veces desproporcionadas y destinadas a sucumbir, pero indispensables para que el "tipo" actual no acabe dominando total y definitivamente la Europa moral y política ${ }^{42}$.

3.

Si el problema fuertemente sentido por Nietzsche es, por tanto, el de la elevación del "tipo" en un sentido opuesto a la masa y sus valores, con vistas a un uso económicamente más ventajoso de las energías en juego, no debemos ocultar que "toda elevación del tipo 'hombre' ha sido, hasta ahora, obra de una sociedad aristocrática" ${ }^{43}$. Nietzsche define a este último como aquel "que cree en una escala jerárquica larga y en una diferenciación de valores entre hombre y hombre", y que "en cierto sentido (in irgend einem Sinne)" tiene necesidad de la esclavitud: pero si su epifanía histórica se encarnó ("eingefleischt") en una diferencia efectiva de casta y de clase, cuya crueldad no se oculta ("Indudablemente, en lo referente a la historia de los orígenes de una sociedad aristocrática (el presupuesto, pues, de esa elevación del tipo 'hombre'), no podemos abandonarnos a ninguna ilusión humanitaria: la verdad es dura" ${ }^{44}$ ), sin embargo, Nietzsche parece dar un aliento más amplio a lo que constituye la Rangordung. Constante amplitud y altura de la mirada; ejercicio en el arte de mandar, pero también de obedecer; elaboración de condiciones cada vez más vastas y distantes: es el patetismo de la distancia, que pertenece hasta tal punto al reino del espíritu, que Nietzsche no duda en definirlo como un ejercicio propio del alma, una excavación de abismos y jerarquías dentro de nosotros mismos. $Y$ entre nuestros impulsos y preferencias ${ }^{45}$.

${ }^{42}$ Como es bien sabido, Nietzsche desarrolla una dialéctica de fuerte oposición entre el individuo y su grupo de pertenencia. Sin embargo, en algunos pasajes poco frecuentes, parece leer el organismo colectivo como funcional y necesario para el nacimiento del individuo. Sólo como miembro de un grupo o de una sociedad es capaz, de hecho, el individuo de madurar su propia emancipación: "es la sociedad la que educa al individuo al principio y lo conforma en individuo, a medias o por completo; ¡NO es que ella consista en seres individuales ni en sus contratos! Más bien, a lo sumo como punto esencial, hace falta un individuo (un cabecilla) y éste es "libre" también sólo en relación al grado más bajo o más alto de los demás"; y, en tono hobbesiano: "no es que el Estado reprima originariamente a lo que diríamos los individuos: ¡éstos todavía no existen en absoluto! Les hace posible la existencia a los hombres, en cuanto animales gregarios. ¡Sólo en él se nos enseñan las pulsiones, los afectos: ¡no son nada originario! ¡Carecen de "estado de naturaleza”! “(FP 11 [182] 1881; cf. también FP 11 [193]). "Todos los Estados y comunidades son algo aún más bajo que el individuo, pero son formas necesarias de su elevación" (FP 7 [98] 1883).

43 JGB 257. Con esta afirmación se abre la novena sección de Más allá del bien y del mal, en la que Nietzsche ilustra "Was ist vornehm".

44 Idem.

${ }^{45}$ En mi opinión, la lectura que hace Losurdo del Pathos der Distanz como signo del proyecto del Nietzsche totus politicus de un "apartheid social" (Losurdo, op. cit., P. 378) resulta completamente inadecuada. (Losurdo, op. cit., p. 378). 
Por lo demás, la constricción y la construcción, la lucha, el arbitrio y la violencia siempre están operando dentro de nosotros: “dominar el caos que se es", dar un estilo al propio carácter ${ }^{46}$, prever una superación y un sometimiento, la imposición de una forma, lograr la victoria y reducir a esclavitud (de ahí "Sklaverei in irgend einem Sinne"). El pathos de la distancia es la voluntad de naturalezas fuertes y dominantes, que logran tener razón sobre sí mismas y por encima de sí mismas, en un ejercicio de poder que es, al mismo tiempo, un acto de creación estética; es propio de las edades fuertes, capaces de reconocer las inevitables amplitudes de tensión que ocurren en la historia y de orientar su curso hacia metas superiores, de cara al futuro.

Justamente lo que le falta a la modernidad: Nietzsche, presenciando las instituciones democráticas y liberales, advierte los costos ("A veces el valor de una cosa no está en lo que se logra con ella, sino en lo que por ella se paga -en lo que nos cuesta" $^{\text {"47 }}$ ) y el pésimo rendimiento, en el sentido caro a él de una economía del espíritu.

Para que haya instituciones ha de haber una especie de voluntad, de instinto, de imperativo, que sea antiliberal hasta la maldad: la voluntad de tradición, de autoridad, de responsabilidad durante siglos, de solidaridad entre cadenas de generaciones hacia delante y hacia atrás in infinitum [...] Todo Occidente ha dejado de tener aquellos instintos de los que nacen las instituciones, aquellos instintos de los que nace el futuro: a su 'espíritu moderno' quizá no haya nada que le vaya tan a contrapelo. Se vive para hoy, se vive muy rápido -se vive de manera muy irresponsable: a eso justamente se llama 'libertad"48.

El contra-movimiento, la inversión de tendencia que Nietzsche considera necesaria -su gran política- es la guerra contra el vicio: "y el vicio es el cristianismo", con todo lo que conlleva desde el punto de vista gnoseológico y moral. "Transvaloración de todos los valores: ésta es mi fórmula para un acto de suprema reflexión de la humanidad sobre sí misma"49, a partir del cual iniciar nuevas construcciones, aunque el propio Nietzsche reconoce el dolor y la dificultad de romper su propio "corazón venerante" ${ }^{50}$. La voluntad de poder, como fuerza organizadora, opera necesariamente dando vida a configuraciones móviles e incesantes, en las que esencialmente leemos "apropiación, ofensa,

46 FW 290.

${ }^{47} \mathrm{GD}$, Incursiones de un intempestivo, 38. El pasaje prosigue con la crítica a las instituciones liberales que, precisamente, se pagan con la pérdida efectiva de la libertad.

${ }^{48} \mathrm{GD}$, Incursiones de un intempestivo, 39.

49 Carta a C. von Seydlitz, 12.02.1888.

50 "Expresándolo como factum brutum: la primera redacción de mi 'Transvaloración de todos los valores' [El Anticristo] está acabada. La concepción global de la obra ha sido, con diferencia, la tortura más larga que he vivido, una verdadera enfermedad. ¡Vosotros, 'hombres del conocimiento' diferentes, vosotros lo tenéis mejor, y la cosa no es tan irracional! Vosotros no conocéis la verdad como algo que uno se arranca trozo a trozo del corazón y en donde toda victoria se cobra venganza con una derrota" (Carta a F. Overbeck, 13.02.1888: CO, 6,990). 
opresión", dureza, incorporación, imposición de formas. Nietzsche no niega que mirar el fundamento puro de la actividad vital (dicho de otro modo, de la "naturaleza desnuda" ${ }^{51}$ ) puede ser inquietante, pero nos invita a considerar los límites de nuestro horizonte cognitivo y de nuestra distorsión moral ${ }^{52}$.

Nietzsche, por tanto, define su posición in politicis como aquella que ve "problemas de poder, de un quantum de poder frente a otro quantum" 53 : una vez más, la dimensión psicofisiológica se muestra prioritaria, abriéndose a lo que será más luego, en la elaboración de Michel Foucault, la biopolítica, entendida como una implicación directa e inmediata entre la dimensión de la política y la de la vida en su caracterización estrictamente biológica ${ }^{54}$.

4.

Un interesante fragmento del otoño de 1887, que encuentra un análogo en un apunte anterior, casa dos fenómenos aparentemente contradictorios: el impulso individualista y la ansiada igualdad de derechos, tal como la sostiene el socialismo.

El individualismo es una forma modesta y aún inconsciente de la "voluntad de poder"; aquí al individuo le parece ya suficiente liberarse de un predominio de la sociedad (ya sea del Estado o de la iglesia...). No se opone como persona,

\footnotetext{
${ }^{51}$ Cfr. FP 9[75] 1887.

52 Nietzsche es perfectamente consciente de cómo la construcción, a lo largo del tiempo, de cadenas ininterrumpidas de significados por parte de la filosofía o del pensamiento común dificulta la comprensión del cambio semántico al que están sometidos determinados conceptos, según los contextos y funciones (véase el caso de las penas en GM). Este sigue siendo, en mi opinión, uno de los problemas más acuciantes de Nietzsche, también en lo que respecta al concepto de Wille zur Macht.

53 "No creemos en un derecho que no descanse sobre el poder de imponerse: consideramos todos los derechos como conquistas con la fuerza" (FP 10[53] 1887). De hecho, llevando su crítica al sistema legal de Eugen Dühring al extremo: "desde el punto de vista biológico más estricto, los casos en que rige el derecho no pueden ser más que casos de excepción, restricciones parciales de la verdadera voluntad de vida, siempre a la busca de poder, a cuyo fin general se hallan, en cuanto medios particulares, subordinados; en cuanto medios para crear unidades de poder mayores. Un orden de derecho pensado como algo soberano y general, no como medio en la lucha de complejos de poder, sino como medio contra toda lucha en absoluto, siguiendo, pongamos, el patrón comunista de Dühring de que toda voluntad debe considerar igual a cualquier otra voluntad, sería un principio hostil a la vida, que traería la destrucción y la disolución al hombre, un atentado contra el futuro de éste, un signo de cansancio, un tortuoso rodeo hacia la nada" _ " (GM II, 11).

${ }^{54}$ Sobre Nietzsche como "pensador biopolítico" véase Vanessa Lemm (Nietzsche y la biopolítica: cuatro lecturas de Nietzsche como pensador biopolitico, "Ideas y Valores", 64 (158), 2015, pp. 223-248), que discute en particular la posición de Roberto Esposito (Bíos. Biopolitica e filosofia, Torino, Einaudi 2004). "Para Esposito, lo político en Nietzsche no es un carácter, una ley o una destinación de algo que está ya siempre dado. Por el contrario, es el poder que informa a la vida desde su comienzo en toda su extensión, constitución e intensidad. En cuanto tales, vida y poder no pueden pensarse independientemente, pues se encuentran anudados de manera inseparable, alterándose e intercambiándose continuamente en una relación constitutiva que no cristaliza en una fundación jurídica de la política" (Lemm, op. cit., p. 227).
} 
sino simplemente como individuo; representa a todos los individuos frente a la colectividad. Es decir: se pone instintivamente como igual a todo individuo; lo que consigue en la lucha no lo consigue como persona, sino como individuo en contra de la colectividad. El socialismo es meramente un medio de agitación del individualista: éste comprende que, para alcanzar algo, hay que organizarse en una acción colectiva, en un "poder". Pero lo que quiere no es la sociedad como fin del individuo, sino la sociedad como medio para hacer posibles muchos individuos: - Éste es el instinto de los socialistas, acerca del cual se engañan con frecuencia [...]. La prédica moral altruista al servicio del egoísmo individual: una de las falsedades más habituales del siglo diecinueve ${ }^{55}$.

Nietzsche, que ahora tiene clara la situación de la modernidad, no se deja engañar por la antítesis. La reivindicación de la igualdad de derechos y el individualismo en realidad no se excluyen: el socialismo tiende a la igualdad, sí, pero de individuos extremadamente vulnerables, vanidades abstractas, por pretenciosas que sean respecto a su valor.

El culpable de este orgullo desmesurado es la distorsión óptica del cristianismo, con su doctrina de la salvación del alma individual, que transforma a cada uno en el centro de gravedad de su propio valor ("Forma extrema de preeminencia del sujeto [...] Forma extrema de la igualdad de derechos, ligados al aumento óptico de la propia importancia hasta el absurdo... Todas almas absurdamente importantes, girando sobre sí mismas con espantoso miedo..."56); son sus sombras las que siguen floreciendo, insospechadas, en los movimientos políticos y sociales contemporáneos:

El delirio político, del que me río lo mismo que los contemporáneos se ríen del delirio religioso de otras épocas, es sobre todo secularización, creencia en el mundo y un quitarse de la cabeza el 'más allá' y el 'trasmundo'. Su meta es el bienestar del individuo FUGAZ: por eso el socialismo es su fruto, es decir, los INDIVIDUOS fugaces quieren conquistar la felicidad por medio de la socialización, no tienen razón alguna para esperar, como la tenían los hombres que disponían de un alma eterna y un devenir eterno y un perfeccionamiento futuro $0^{57}$.

En un mundo desdivinizado, Nietzsche se enorgullece de haber llevado a cabo un reconocimiento y una enucleación del ideal cristiano, incluso ahí donde ha hecho tabula rasa de su forma dogmática, y de haber emprendido una lucha

${ }^{55}$ FP 10[82] 1887. Cfr. anche FP 40[26] 1885.

${ }^{56}$ FP 11[226] 1887-88.

${ }^{57}$ FP 11[163] primavera-otoño de 1881. Por el contrario, Nietzsche: “[...] La religión, pensada como continuación y profundización de la doctrina política fundamental, que es siempre la doctrina de la desigualdad de derechos, de la necesidad de una construcción social con un arriba y un abajo, con unos que mandan y otros que obedecen; religión significa para nosotros la doctrina de la diferencia jerárquica de las almas, de la cría y posibilitación de almas superiores a costa de las inferiores" (FP 3[13] 1885). 
contra los residuos del cristianismo latente ${ }^{58}$. Su fuerte oposición va dirigida contra cualquier síntoma de cansancio fisiológico, de empobrecimiento de la voluntad, de rancune [rencor] que venga a dar en "revolución, idea moderna y principio de decadencia de todo el orden social" 59 : esto, que es principalmente "dinamita cristiana", socava los cimientos de una construcción ya precaria, de un edificio válido sólo para hoy; un ideal respecto al cual el filósofo, "hombre necesario del mañana y del pasado mañana", no puede hallarse sino en contradicción ${ }^{60}$.

Nietzsche puede así hablar, en varios lugares, de una "nueva Ilustración", en la que, gracias al desenmascaramiento de las mentiras morales, se le restituye al cuerpo del hombre europeo -in physologicis- la energía que le ha sido sustraída ${ }^{61}$. Sólo entonces podrá surgir el "individuo soberano" -una figura no fácilmente traducible dentro de la ciencia política moderna: no aquel que simplemente se ha liberado de un poder restrictivo (ya sea estatal, moral o religioso), sino el que asume la plena responsabilidad de esta misma coacción, que produce por sí y para sí su propia ley, poniéndose como subjetividad renovada.

Situémonos [...] al final de ese proceso formidable, allí donde el árbol por fin da sus frutos, donde la sociedad y su moralidad de la costumbre pone por fin a la luz de qué eran sólo un medio: encontraremos entonces que el fruto más maduro del árbol es el individuo soberano, igual sólo a sí mismo, liberado der la moralidad de la costumbre, autónomo, supra-moral (pues "autónomo" y "moral" se excluyen), en una palabra, encontraremos al hombre de la voluntad propia, independiente, duradera, que se puede permitir hacer promesas - y en él, palpitando en todos los músculos, una conciencia orgullosa de lo que ha acabado por lograr y se ha hecho carne en él, una conciencia verdadera de poder y libertad, un sentimiento de plenitud del hombre como tal ${ }^{62}$.

Después de haber ilustrado la barbarie con la que se quiso forjar, en el hombre, su mala conciencia (“dureza, tiranía, torpeza e idiotez”), Nietzsche propone, por tanto, un nuevo concepto de consciencia, ya no fruto de la doma tiránica del animal-hombre, fruto maduro y meta de este "inmenso proceso": un "individuo" real, en el que la buena conciencia del propio valor y de la propia libertad se encarnan, "palpitando en cada músculo", haciéndose "carne y sangre" y no mera etiqueta moral.

\footnotetext{
58 "El socialismo moderno quiere crear la subforma mundana del jesuitismo: cada uno, instrumento absoluto. Pero hasta ahora no se ha encontrado el fin. ¡¿Para qué?!” (FP 25[263] 1884).

${ }^{59} \mathrm{AC} 62$.

${ }^{60}$ Cfr. JGB 212.

${ }^{61}$ Cfr. FP 27[80]; 25[294] 1884.

62 GM II, 2.
} 
Una transvaloración de valores, por tanto, para ser implementada in physiologicis: éste es, en mi opinión, el propósito de la batalla de Nietzsche contra la moral gregaria y el resultado de su gran política ${ }^{63}$. Todo lo contrario de su pretendido anti-humanismo: más bien, la restitución, al hombre, de un legítimo señorío sobre sí mismo y sobre las circunstancias, y la genuina buena conciencia de su propia legitimidad como donador de sentido e intérprete de su propia forma de vida.

[Traducción del italiano de Manuel Barrios Casares]

${ }^{63}$ Si la figura del individuo soberano parece mantener más de una ambivalencia y situarse en el espacio utópico del "Sollen" que remite al futuro (Vittoria Franco "L'individuo sovrano e la sua impossibilità. Friedrich Nietzsche". En: Etiche possibili: il paradosso della morale dopo la morte di Dio, Roma, Donzelli, pp. 45-78: 45-46), eso es porque el tipo gregario aún domina en la modernidad: Nietzsche tiene que resolver el poder excesivo de éste último, antes de poder augurar nuevas figuras éticas. Por eso, la batalla que se desarrolla en El Anticristo se vuelve decisiva en este sentido (no en vano, toda la Transvaloración), cuyo resultado favorable podría "cambiar la forma de contar los años" y "cortar en dos el curso de la historia". 


\section{Referencias bibliográficas:}

Acampora, Christa Davis, "Demos Agonistes Redux: Reflections on the Streit of Political Agonism", en Nietzsche-Studien, 32 (2003), pp. 373-89.

Ansell-Pearson, Keith, An Introduction to Nietzsche as political Thinker. The perfect nihilist, Cambridge, Cambridge University Press 1994.

Bobbio, Noberto, "Stato, potere e governo", en: Stato, governo, società. Frammenti di un dizionario politico, Turín, Einaudi 1985.

Campioni, Giuliano, Sulla strada di Nietzsche, Pisa, ETS 1993.

Campioni, Giuliano, Der französische Nietzsche, Berlin/New York, Walter de Gruyter, 2009.

Conway, Daniel W., Nietzsche \& the Political, London, Routledge 1997.

Esposito, Roberto, Bíos. Biopolitica e filosofia, Turín, Einaudi, 2004.

Fornari, Maria Cristina, La morale evolutiva del gregge. Nietzsche legge Spencer e Mill, Pisa, ETS 2006.

Franco, Vittoria, "L'individuo sovrano e la sua impossibilità. Friedrich Nietzsche". In: Etiche possibili: il paradosso della morale dopo la morte di Dio, Roma, Donzelli, pp. 45-78.

Gentili, Carlo, Grande politica e pathos della distanza. La concezione politica e morale di Nietzsche, "Palomar", Vol. 2/3 (2005), pp. 96-106.

Gentili, Carlo, Nietzsche politico o apolitico? "Estudios Nietzsche" 12 (2012), pp. 10-11.

Gori, Pietro; Stellino, Paolo, Il buon europeo di Nietzsche oltre nichilismo e morale cristiana, "Giornale critico della filosofia italiana", 7 serie, vol. XII, a. 95 (1), 2016, pp. 98-124.

Lemm, Vanessa "Nietzsche y la biopolítica: cuatro lecturas de Nietzsche como pensador biopolítico", en Ideas y Valores, 64 (158), 2015, pp. 223-248.

Losurdo, Domenico, Nietzsche, il ribelle aristocratico. Torino, Bollati Boringhieri 2002.

Mill, John Stuart, Gesammelte Werke, Leipzig, Fues, 1869-1880.

Ottmann, Henning, Philosophie und Politik bei Nietzsche, Berlin, de Gruyter 1987.

Siemens, Herman, Nietzsche and Agonistic Politics: A Review of Recent Literature, "Nietzsche-Studien", 30 (2001), pp. 509-526: 510-11. 
